\title{
ANALISIS LOG PENERBANGAN PADA UNMANNED AERIAL VEHICLE (UAV) SEBAGAI BARANG BUKTI DIGITAL
}

\author{
Septyan Eka Prastya ${ }^{1)}$, Subhan Panji Cipta ${ }^{2)}$, dan Bayu Nugraha ${ }^{3)}$ \\ ${ }^{1,2)}$ Teknologi Informasi, Universitas Sari Mulia Banjarmasin \\ ${ }^{3)}$ Sistem Informasi, Universitas Sari Mulia Banjarmasin \\ 1,2,3) Jl. Pramuka No.2, Pemurus Luar, Kec. Banjarmasin Tim., Kota Banjarmasin, Kalimantan Selatan \\ e-mail: septyan_iyas@ rocketmail.com ${ }^{1)}$, panji.cipta@gmail.com ${ }^{2)}$, naigaxeon@gmail.com ${ }^{3)}$
}

\begin{abstract}
ABSTRAK
Pada beberapa akhir ini, penggunaan perangkat drone oleh masyarakat umum meningkat dengan sangat pesat, presentasi total dari penjualan terus meningkat pesat dari tahunnya, total dari penjualan drone di tahun 2020 diperkirakan akan menyentuh angka \$2.28 Bilion. Dengan peningkatan sebesar itu, kemungkinan akan terjadinya penyalahgunaan Unmanned Aerial Vehicle $(U A V)$ dalam menjalankan tindak kejahatan semakin besar. Dari analisis forensik data dengan menggunakan metode static forensic dan live forencic untuk mendapatkan data yang memungkinkan untuk digunakan sebagai barang bukti digital. Diharapkan dapat menggali informasi yang bisa digunakan sebagai barang bukti digital pada UAV dan kontroler, serta mengetahui karakteristik bukti digital pada UAV. Hasil yang menampilkan bahwa terdapat perangkat smartphone yang digunakan sebagai kontroler UAV memiliki peranan yang penting dalam investigasi. Karena didalam perangkat tersebut memiliki nilai informasi bukti digital yang lengkap jika dibandingkan dengan media penyimpanan yang terdapat pada perangkat UAV lainnya. Contohnya dalam penggunaan perangkat drone DJI Phantom 3 Advanced selalu menggunakan GPS pada penerbangannya, file gambar maupun video yang diambil menggunakan kamera pesawat pasti memiliki koordinat lokasi GPS pada metadata didalamnya.
\end{abstract}

Kata kunci: Unmanned Aerial Vehicles (UAV), Log, Forensic, GPS

\begin{abstract}
In recent years, the use of drone devices by the general public has increased very rapidly, the entire presentation of sales continues to overgrow from the total, the total sales of drones in 2020 is expected to generate $\$ 2.28$ billion. With such an increase, spending will be spent while flying Unmanned Aerial Vehicles (UAVs) in carrying out the increasingly high crime. From the forensic analysis of data using static forensic and direct forensic methods to obtain data that can be used as digital evidence. It is expected to help information that can be used as digital evidence on UAVs and controllers, and understand the characteristics of digital evidence on UAVs. The results show that there is a smartphone device that is used as a UAV controller has a vital role in the investigation. Because it is inside this device, it has full digital evidence information value with the storage media that is in other UAV devices. For example, in the use of DJI Phantom 3, Advanced drone devices always use GPS on their flights, image, or video files taken using aircraft cameras must have GPS location coordinates on the metadata in them.
\end{abstract}

Keywords: Unmanned Aerial Vehicles (UAV), Log, Forensic, GPS

\section{Pendahuluan}

$\mathrm{U}$ nmanned Aerial Vehicles (UAVs) atau juga bisa disebut dengan perangkat drone merupakan pesawat terbang dengan bobot kecil tanpa pilot. Perangkat ini paling banyak digunakan di bidang militer maupun orang-orang penggemar dari suatu hobi fotografi atau videografi. Pada beberapa tahun terakhir ini, penggunaan drone oleh masyarakat sipil meningkat dengan pesat, sampai disebutkan oleh UK House of Lords bahwa tahun 2014 merupakan "Tahun dari drone"[1] 
Pada tahun 2015 majalah Forbes pada situsnya menuliskan distribusi penjualan salah satu pemegang hak paten merk drone dari awal berdirinya hingga saat ini. Pada awal penjualannya pada tahun 2009 sampai dengan tahun 2010, presentasi penghasilan per tahun sekitar lebih dari 50\% dari total penjualan keseluruhan terdapat di North American. Adapun di tahun 2011 presentase dari hasil penjualan tahunan meningkat sampai dengan $280 \%$, sedangkan presentasi penjualan di North American hanya sekitar 30\% dari total penjualan. Presentasi total penjualan terus meningkat pesat setiap tahunnya, penjualan drone pada tahun 2020 diperkirakan akan menyentuh \$2.28 Bilion.[2]

Perangkat drone dapat bekerja menjadi dua bagian, yang pertama yaitu awak pesawat drone itu sendiri dan controller yang mempunyai fungsi untuk mengendalikan awak pesawat drone [3]. Pada beberapa tipe drone, ada yang sudah tidak memerlukan controller lagi untuk mengendalikan awak pesawatnya. Drone tipe ini menggunakan pemancar GPS yang terpasang pada penggunanya, jadi ketika drone ini di aktifkan, awak pesawatnya bekerja otomatis mengikuti ke mana pun arah dari pengguna yang menggunakan pemancarnya. Drone dengan cara kerja seperti ini pasti memiliki banyak sensor di awak pesawatnya, yang berguna dalam menjaga perangkat drone aman saat diterbangkat di lingkungan sekitar oleh penggunanya.

Bukti digital yang bisa diambil dari awak pesawat drone adalah ID dari drone itu sendiri, ID Drone, letak posisi saat drone diterbangkan, image ataupun video yang di ambil ketika drone diterbangkan, log update software yang digunakan. Sedangkan pada controller nya bisa ditemukan bukti digital berupa storage penyimpanan image atau video yang diambil menggunakan drone, log lokasi penggunaan drone, perangkat lunak (software) yang difungsikan dalam mengatur kendali drone, ID dari drone yang pernah terhubung.

Paper ini menjelaskan mengenai menggali informasi dan melakukan analisis terhadap bukti digital yang terdapat pada drone beserta controller nya dengan menggunakan metode static forensic dengan upaya untuk memberilan informasi pada aktivitas forensik GPS yang menggunakan drone.

\section{Metodologi PENELITIAN}

1. Skenario

Untuk melakukan simulasi maka dibuat skenario dari penggunaan drone, adapun skenario penggunaan UAV pada penelitian ini akan dijelaskan seperti gambar 1

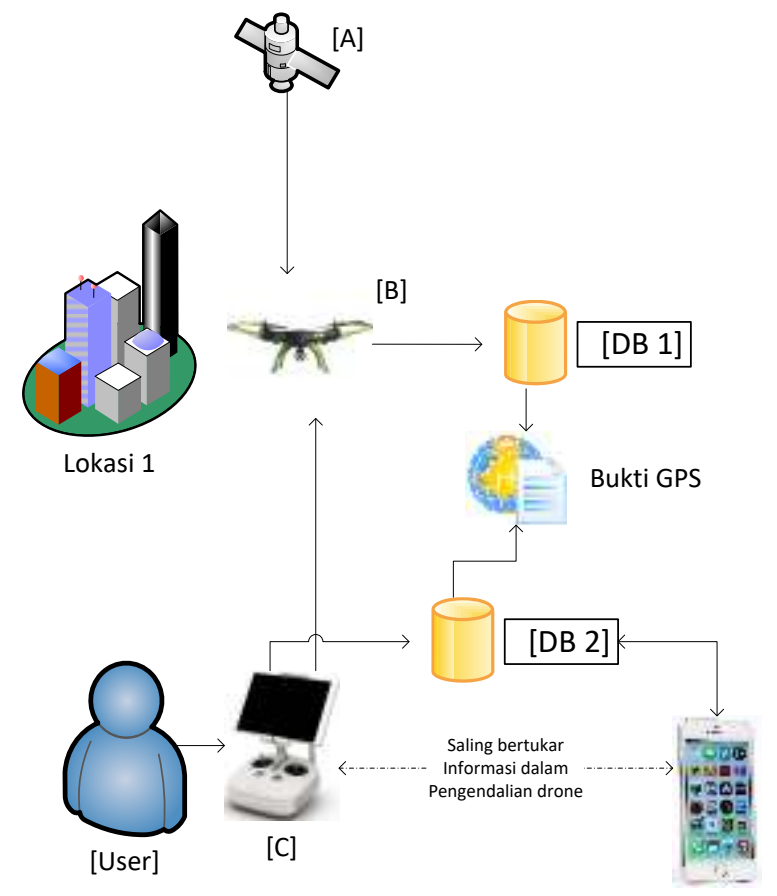

[D]

Gambar 1. Skenario penggunaan UAV

Pada tahapan yang dirancang yaitu dioperasikannya drone untuk melakukan beberapa penerbangan dan mengambil gambar serta video di lokasi tersebut. Disetiap lokasi tersebut, pada saat diterbangkan sensor navigasi 
di dalam drone akan mendapatkan data berupa lokasi dari satelit GPS dan GLONASS yang kemudian disimpan ke dalam database pada drone. Sedangakan untuk database ground station yang berupa kontroler untuk mengendalikan penerbangan drone dan smartphone untuk menerima streaming sinyal video dari drone serta mengontrol setting pada kamera drone[3].

Hasil analisis yang diharapkan terdapat pada UAV dan kontroler yaitu berupa:

- File Gambar

- Lokasi penerbangan UAV dilakukan

- Nilai sensor posisi yang digunakan UAV

- Struktur konfigurasi penerbangan UAV

- Kondisi harware dan software UAV

- FIle Video

- ID UAV dan kontroler

Untuk mendapatkan karakter penyimpanan data-data lokasi pada log didalam storage UAV dari penggunaan drone maka dilakukan lah beberapa skenario penerbangan menggunakan 3 mode terbang yang tersedia pada DJI Phantom 3 Advanced. Berdasar User Manual DJI Phantom 3 Advaced [4], tiga mode terbang tersebut yaitu berupa:

- P-mode (Positioning) : Bekerja terbaik ketika sinyal GPS yang diterima. Terdapat tiga versi berbeda dari P-mode, yang akan dipilih secara otomatis oleh Phantom 3 Advanced berdasar kekuatan sinyal dan Vision Positioning Sensor, yaitu:

- P-GPS : GPS dan Vision Positioning keduanya tersedia, awak pesawat menggunakan perangkat GPS untuk menentukan posisi.

- P-OPTI : Vision Positioning tersedia tetapi sinyal GPS tidak tersedia, awak pesawat hanya menggunakan Vision Positioning untuk menahan lokasinya.

- P-ATTI : GPS dan Vision Positioning tidak tersedia, awak pesawat hanya menggunakan barometer untuk penentuan lokasi, jadi hanya ketinggian yang diatur.

- A-mode (Attitude) : GPS dan Vision Positioning System tidak digunakan untuk stabilisasi. Awak pesawat hanya menggunakan barometer nya untuk stabilisasi. Awak pesawat masih bisa otomatis kembali ke Home Point apabila lokasi Home Point sudah terekam

- F-mode (Function) : dimana Intelligent Orientation Control (IOC) diaktifkan pada mode ini. Pilihan mode yang tersedia ketika Intelligent Orientation Control (IOC) diaktifkan.

\section{HASIL DAN PEMBAHASAN}

1. Skenario

Skenario yang dirancang yaitu melalui beberapa aktifitas yang dilakukan menggunakan 3 (tiga) mode berbeda pada saat penerbangan. Penerbangan pertama menggunakan konsep P-mode (Positioning), pada mode ini menggunakan GPS dan Visioning Position System (VPS) yang bekerja secara bersamaan.

2. Akuisisi

Proses akuisisi pada UAV dilakukan pada tiga bagian, yang pertama pada awak pesawat yang digunakan selama penerbangan. Yang kedua media penyimpanan kamera yang digunakan pada awak pesawat. Dan yang ketiga adalah pada kontroler atau ground station yang disini adalah menggunakan model smartphone Lenovo P70.

Proses akuisisi pada storage awak pesawat dan memory card yang terdapat pada awak pesawat dilakukan dengan cara physical (sector per sector atau bit-stream copy) sehingga hasil imaging akan sama persis dengan barang bukti secara physical. File iamging disimpan dengan ektensi .dd [5]

\section{Analisis}

\section{1) GPS Evidence Extraction}

Pada Log yang berisi data informasi GPS memiliki ekstensi file .DAT pada storage awak pesawat dan file dengan ekstensi .txt pada smartphone. 


\section{A. P-mode (position)}

Pada log yang terdapat di dalam awak pesawat dilakukan analisa dengan membaca file FLY019.log.txt hasil penggunaan aplikasi DatCon pada file FLY019.DAT diketahui mode penerbangan, lokasi home point yang terekam, dan durasi dari penerbangan. Untuk lebih detail dapat dilihat pada Gambar 2 berikut ini:

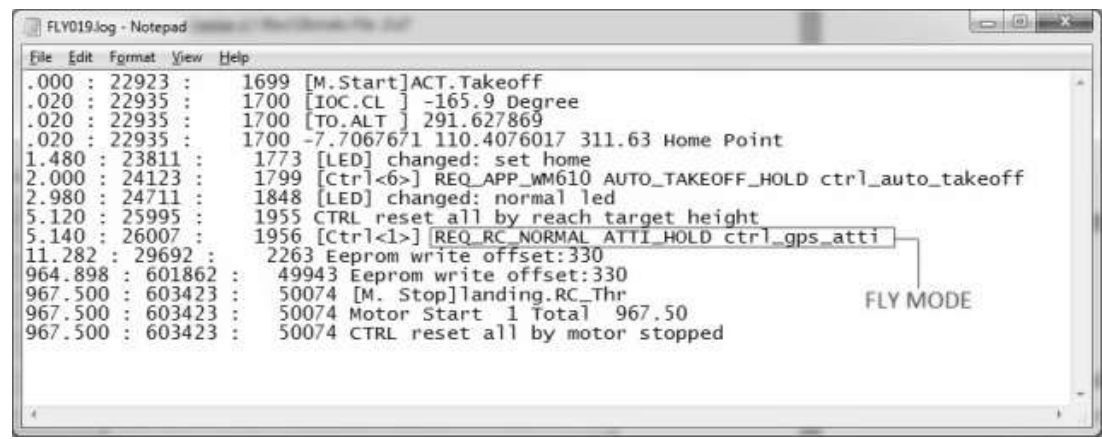

Gambar 2. Hasil Event Log

Didalam log yang terdapat pada media penyimpanan UAV dapat dilihat kumpulan koordinat jalur penerbangan untuk mendapatkan list koordinat dengan format file .csv pada tabel 1.

Tabel 1. Hasil Log Koordinat Penerbangan

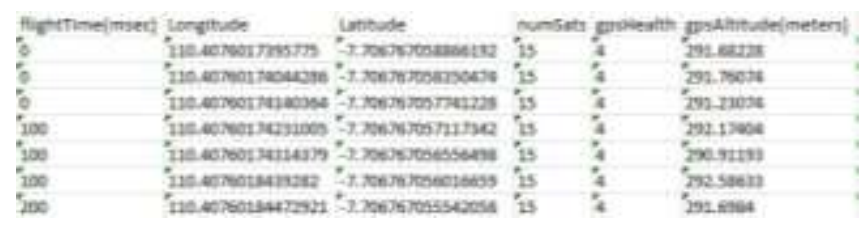

B. A-mode (Attitude)

Pada log yang terdapat didalam awak pesawat dilakukan analisa dengan membaca file FLY021.log.txt hasil penggunaan aplikasi DatCon pada file FLY021.DAT diketahui mode penerbangan, lokasi home point yang terekam, dan durasi dari penerbangan. Untuk lebih detail dapat dilihat pada Gambar 3 berikut:

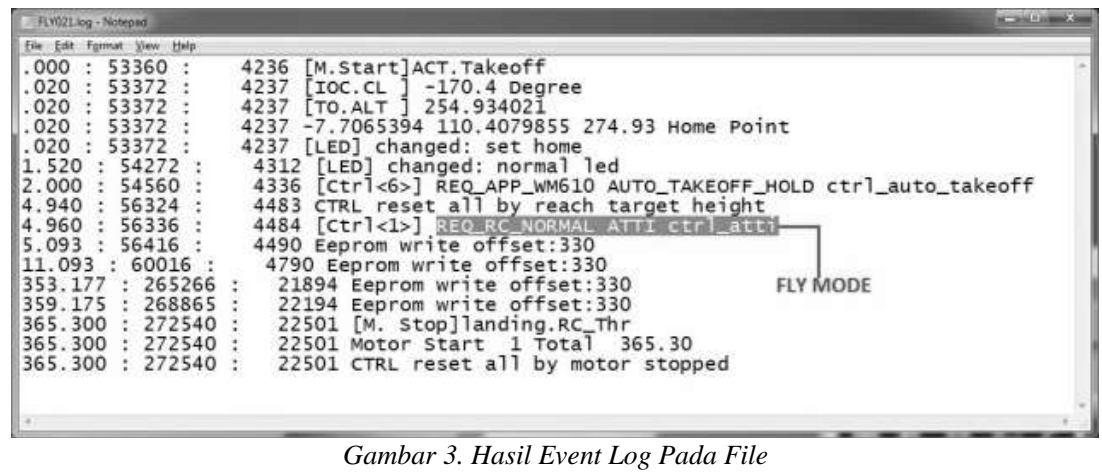

Sedangkan untuk jalur penerbangan dengan mode ini juga masih dapat ditemukan dengan proses yang sama dengan sebelumnya. Untuk hasil lebih detail dapat dilihat pada tabel 2.

Tabel 2. Hasil Log Koordinat Penerbangan Pada File FLY021.DAT

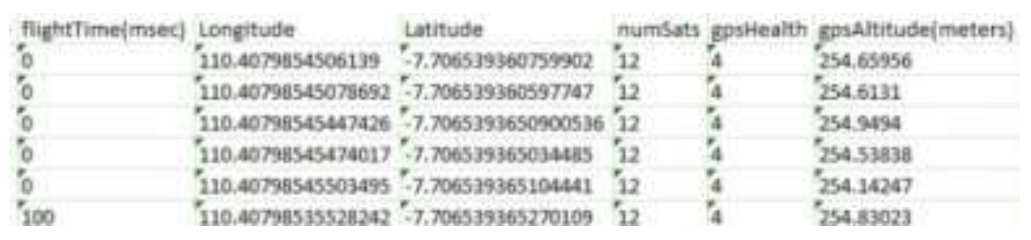




\section{F-mode (Function)}

untuk jalur penerbangan dengan mode ini juga masih dapat ditemukan dengan proses yang sama dengan sebelumnya. Yaitu dengan mengunggah file log FLY022.DAT ke aplikasi berbasib web pada alamat https://www.mapsmadeeasy.com/log_viewer untuk mendapatkan list koordinat dengan format file .csv. Untuk hasil lebih detail dapat dilihat pada tabel 3.

Tabel 3. Hasil Log Koordinat Penerbangan Pada File FLY022.DAT

\begin{tabular}{|c|c|c|c|c|c|}
\hline flightTime(msec) & Longitude & Latitude & numSats & gpsHealth & gpsAltitude(meters) \\
\hline '0 & 110.40707084597868 & -7.706645369360192 & 15 & 5 & 269.2901 \\
\hline 0 & 110.40707074573865 & -7.70664527046292 & 15 & 5 & 269.0068 \\
\hline '0 & 110.40707074552596 & 7.706645271576586 & 15 & 5 & 268.85355 \\
\hline 0 & 110.40707074530957 & -7.706645272686291 & 15 & 5 & 268.06805 \\
\hline "0 & 110.40707074506453 & -7.706645273819164 & 15 & '5 & 267.91782 \\
\hline 100 & 110.40707074495123 & -7.706645275034132 & 15 & 5 & 269.59763 \\
\hline 100 & 110.40707074505286 & -7.706645276170914 & 15 & 5 & 267.97226 \\
\hline
\end{tabular}

\section{2) GPS Evidence Conversion}

Analisis selanjutnya yang dilakukan adalah melakukan konversi file selain file log yang terdapat pada storage awak pesawat, kartu memori kamera dan smartphone. Metode ini dilakukan dengan membaca metadata file yang mengandung informasi lokasi atau GPS, file tersebut bisa berupa gambar, video, dan lain-lain. Secara detail, informasi koordinat GPS pada file .dd dapat dilihat pada gambar 4 berikut:

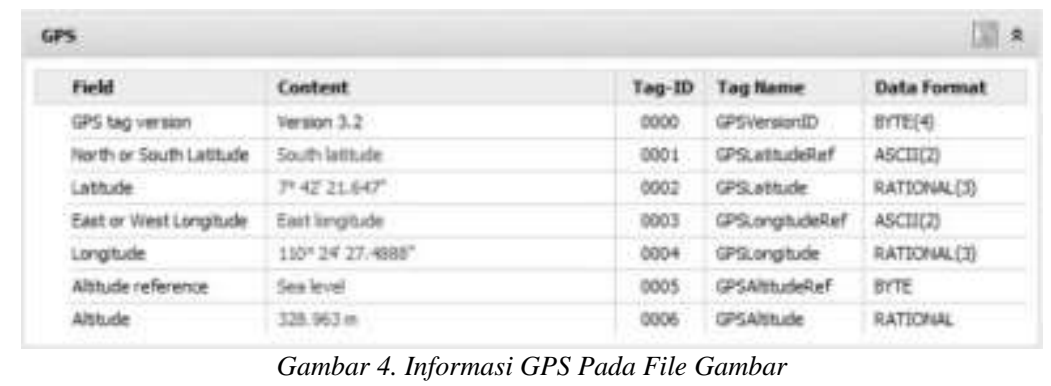

\section{GPS Evidence Presentation}

Setelah melalui proses ektraksi dan konversi bukti digital GPS, tahap berikutnya yang dilakukan adalah menyajikannya dalam bentuk presentasi. Dalam digital forensic presentasi merupakan serangkaian kegiatan yang dilakukan oleh ahli forensik dalam mendemontrasikan temuannya di dalam pengadilan guna menerangkan suatu perkara dalam membantu hakim dalam mengambil keputusan.

A. Data log pada smartphone

Didalam penelitian ini penulis menggunakan alamat website https://healthydrones.com/ untuk menampilkan informasi penerbangan yang tersimpan didalam log file DJIFlightRecord yang terdapat didalam smartphone. Adapun untuk informasi penerbangan dapat dilihat pada gambar berikut. 


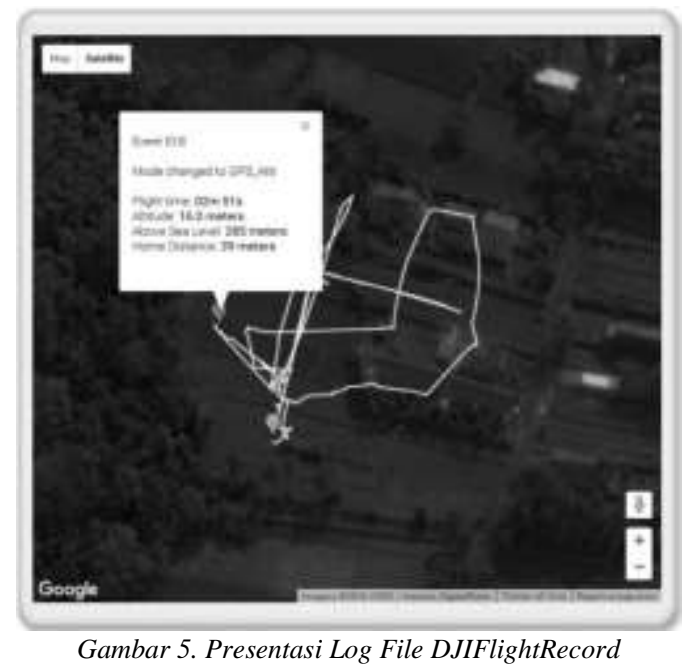

B. Data log pada awak pesawat

Untuk log file dengan ekstensi .DAT yang terdapat didalam storage UAV dapat menggunakan alamat situs https://www.mapsmadeeasy.com/log_viewer dalam menyajikan lokasi, jalur terbang, kecepatan, ketinggian, dan berbagai macam infomasi berguna sebagai barang bukti UAV.

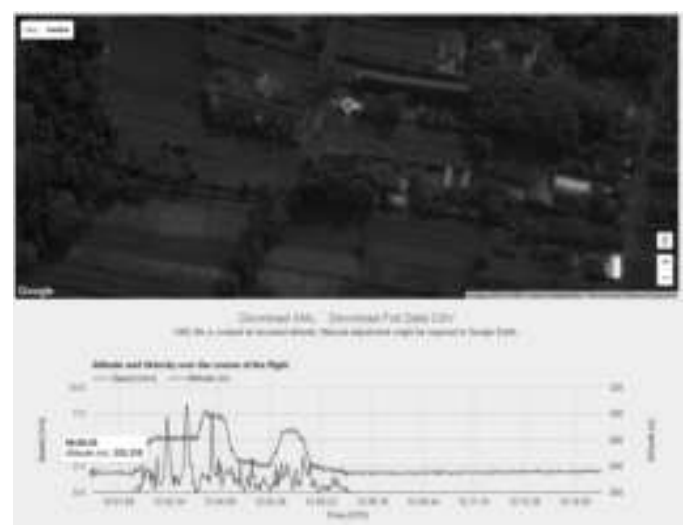

Gambar 6. Presentasi Log File FLY021.DAT

C. Data hasil konversi gambar pada UAV

Untuk presentasi informasi GPS dari hasil konversi file gambar yang diambil oleh kamera UAV, digunakan aplikasi Google Maps. Pada Gambar 7 dapat dilihat hasil lokasi dari koordinat.

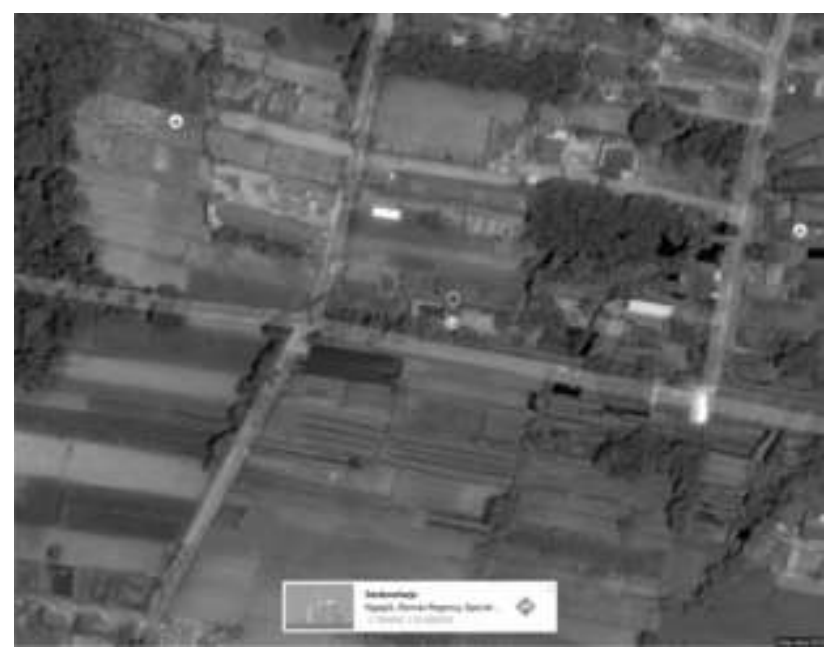

Gambar 7. Informasi Data GPS File 


\section{Karakteristik Bukti Digital}

Adapun karakteristik bukti digital GPS yang diketahui dari UAV secara terperinci sebagai berikut:

a) Bukti digital GPS sangat rentan mengalami perubahan terhadap perpindahan tempat, sedikit pergerakan dapat berpengaruh terhadap perubahan titik latitude dan longitude.

b) Pada DJI Phantom 3 Advance, koordinat GPS dan informasi data penerbangan selalu ditulis kedalam log didalam storage awak pesawat dan log didalam smartphone. Data akan terus ditulis dan disimpan walaupun mode penerbangan yang digunakan tidak memakai sinyal GPS untuk stabilitas awak pesawat.

c) Pada storage awak pesawat informasi log penerbangan tersimpan didalam file dengan ekstensi .DAT, sedangkan informasi log penerbangan pada kontroler tersimpan didalam folder aplikasi DJI dengan ekstensi .txt

d) Pada kartu memori kamera yang terdapat pada UAV, bukti digital GPS yang didapatkan harus memalui proses konversi metadata dari file gambar ataupun video yang terdapat didalamnya. Bukti digital di dalam storage ini hanya berupa koordinat lokasi latitude dan longitude pada saat file gambar atau video diambil.

e) Informasi bukti digital yang didapat dari smartphone sebagai kontroler memiliki tingkat kekayaan informasi yang lebih jika dibandingkan dengan informasi yang didapat dari storage awak pesawat ataupun kartu memori pada kamera UAV.

Detail perbandingan informasi yang didapat dari storage awak pesawat, kartu memori kamera, dan media penyimpanan didalam aplikasi DJI pada smartphone dapat dilihat pada Tabel 4

Tabel 4 Perbandingan Bukti Digital Pada UAV

\begin{tabular}{|c|c|c|c|}
\hline \multirow{2}{*}{ Infromasi Bukti Digital } & \multicolumn{3}{|c|}{ Storage } \\
\cline { 2 - 4 } & UAV & $\begin{array}{c}\text { Memory } \\
\text { Card }\end{array}$ & $\begin{array}{c}\text { Smart } \\
\text { phone }\end{array}$ \\
\hline Metode akuisisi & Live & Static & Live / Static \\
\hline Jenis image & Physical & Physical & Logical \\
\hline Format image & .dd & .dd & .ad1 \\
\hline Tool Akuisis & $\begin{array}{c}\text { FTK } \\
\text { Imager }\end{array}$ & $\begin{array}{c}\text { FTK } \\
\text { Imager }\end{array}$ & FTK Imager \\
\hline Lokasi GPS & $\sqrt{ }$ & $\sqrt{ }$ & $\sqrt{ }$ \\
\hline Log koordinat jalur penerbangan & $\sqrt{ }$ & - & $\sqrt{ }$ \\
\hline Informasi konfigurasi UAV & $\sqrt{ }$ & - & $\sqrt{ }$ \\
\hline Gambar atau video & - & $\sqrt{ }$ & $\sqrt{ }$ \\
\hline Informasi mode penerbangan & $\sqrt{ }$ & - & $\sqrt{ }$ \\
\hline Informasi pengguna UAV & - & - & $\sqrt{ }$ \\
\hline Informasi data penerbangan & $\sqrt{ }$ & - & $\sqrt{ }$ \\
\hline UAV & & - & $\sqrt{ }$ \\
\hline Arah pengambilan gambar & - & - & \\
\hline Informasi Kekuatan sinyal UAV & - & - & \\
\hline Informasi kondisi sensor UAV & - & - & \\
\hline Informasi kondisi daya UAV & $\sqrt{ }$ & & \\
\hline Informasi kondisi kontroler & - & & \\
\hline UAV & & & \\
\hline
\end{tabular}

\section{KESIMPULAN}

Didalam media penyimpanan yang terdapat pada UAV, baik itu di dalam kartu memori, awak pesawat, atau kontroler. Banyak tersimpan berbagai barang bukti digital GPS dan informasi-informasi berharga lainnya yang bisa digunakan sebagai barang bukti digital apabila terjadi penyalah gunaan UAV. Dengan menggunakan metode static forensic, barang bukti digital GPS berupa koordinat lokasi pengambilan gambar masih bisa ditemukan dengan melakukan konversi file gambar yang terdapat didalam kartu memori kamera UAV. Akan tetapi log penerbangan yang terdapat didalam storage awak pesawat dan kontroler tidak bisa dilakukan akuisisi dengan metode static karena 
untuk melakukannya, sistem harus dihidupkan. Dilihat dari karakteristik bukti digital pada UAV, pada perangkat smartphone yang digunakan untuk melakukan proses kontroler UAV mempunyai peranan yang penting dalam proses investigasi. Karena pada perangkat tersebut memiliki nilai informasi bukti digital yang lebih lengkap jika dibandingkan dengan media penyimpanan yang terdapat pada perangkat UAV lainnya. DJI Phantom 3 Advanced akan melakukan penyimpanan data koordinat GPS pada LOG penerbangannya, data tersebut akan selalu disimpan bahkan ketika mode penerbangan yang digunakan tidak menggunakan sinyal GPS untuk proses stabilitasnya. Dikarenakan DJI Phantom 3 Advanced selalu menggunakan GPS pada penerbangannya, file gambar maupun video yang diambil menggunakan kamera pesawat pasti mempunyai koordinat lokasi GPS pada metadata di dalamnya.

\section{DAFTAR PUSTAKA}

[1] G. Horsman, "Unmanned aerial vehicles: A preliminary analysis of forensic challenges," Digit. Investig., vol. 16, pp. 1-11, 2016.

[2] H. Shao, "Drone Overlord Frank Wang On DJI's Milestones, Miscarried GoPro Partnership \& Corporate Espionage," Forbes Asia, 2015.

[3] M. A. Lukmana and H. Nurhadi, "Rancang Bangun Unmanned Aerial Vehicle ( UAV )," pp. 1-5.

[4] DJI, Phantom 3 User Manual, 2015.

[5] Sukriadi and Y. Prayudi, “Analisis Bukti Digital Global Positioning System ( GPS ) Pada Smartphone Android,” Kns\&I Stikom, no. 11, 2014. 